\title{
Can hierarchy hold back the dynamics of self- reinforcing processes? A simulation study on path dependence in hierarchies
}

\author{
Arne Petermann ${ }^{1} \cdot$ Georg Schreyögg ${ }^{2,3}$. \\ Daniel Fürstenau ${ }^{4}$ (D)
}

Received: 2 August 2016/Accepted: 4 January 2019/Published online: 23 January 2019

(C) The Author(s) 2019

\begin{abstract}
Theories of path dependence and incumbent inertia assume that self-reinforcing mechanisms lead to highly persistent and eventually inefficient institutional solutions. The resulting lock-in is likely to threaten the viability of an organization. While path dependence theory was initially developed as a market-based approach, it has more recently been transferred to institutional settings and in particular to hierarchies. Some critics doubt, however, its applicability to hierarchical organizations. The major argument states that asymmetric power structures in organizations differ significantly from symmetric coordination modes and autonomous evolutionary dynamics. Hierarchical authority is assumed to be stronger and to rule out emergent autonomous dynamics. This reasoning raises the question whether hierarchical structures are actually strong enough to suppress (deliberately) the power of evolutionary self-reinforcing organizational dynamics, or vice versa. To our knowledge, there are no studies to date examining in detail these reverse dynamics. In this paper, we build on simulations to study these competing dynamics and possible conditions that favor one view or the other. We suggest using agent-based simulation and
\end{abstract}

Daniel Fürstenau

daniel.fuerstenau@fu-berlin.de

Arne Petermann

arne.petermann@bagss.de

Georg Schreyögg

georg.schreyoegg@fu-berlin.de

1 Berufsakademie für Gesundheits- und Sozialwesen Saarland (BAGSS), Fischbacher Str. 100, 66287 Quierschied, Germany

2 School of Business, Economics and Social Sciences, University of Graz, Elisabethstr. 50, 8010 Graz, Austria

3 Freie Universität Berlin, Berlin, Germany

4 School of Business and Economics, Freie Universität Berlin, Garystr. 21, 14195 Berlin, Germany 
modeling, conceiving of institutional change as an interdependent multi-level process that can be analyzed numerically. The results indicate that in most situations selfreinforcing organizational dynamics can actually overrule hierarchical authority, whilst in some other situations formal authority proves to be stronger.

Keywords Path dependence $\cdot$ Self-reinforcing processes $\cdot$ Complementarities Hierarchy $\cdot$ Agent-based modeling

\section{Introduction}

Agility and adaptability feature prominently in the current managerial discourse (Eisenhardt and Martin 2000; Reeves and Deimler 2011; Worley et al. 2014). However, an increasing number of studies highlight opposing conditions: impediments, inertia, and the inability to adapt to a changing environment (Tripsas and Gavetti 2000; Danneels 2011; Stieglitz et al. 2016; Eggers and Park 2018). These are unintended phenomena resulting from emergent, evolutionary social dynamics. Among the approaches aiming to explain such emerging organizational rigidities, the theory of path dependence (David 1985) has recently come to the fore. Combining the logic of positive feedback ("increasing returns", Arthur 1989) with the "history matters" argument, the concept of path dependence provides a distinct explanation of the intricate process of gradual persistence, leading eventually to lock-in. Initially developed to explain the puzzling persistence of inefficient standards in technology markets (David 1985; Arthur 1989; Cusumano et al. 1992; Fouquet 2016), path dependence has recently been increasingly applied to inert phenomena in organizations such as strategic decision making, staff selection modes, organizational design policies, and persistent rule preferences. Examples include Intel's reduced scope for seizing and adopting new businesses, which resulted in strategic inertia (Burgelman 2002), or informal homophilic policies in staff recruiting, which brought about hyperstability in the composition of the top management of a professional service firm (Erfurt Sandhu 2014), or the failing attempts to adapt the business model of Bertelsmann Book Club to changes in the market of printed media (Schreyögg et al. 2011). In most cases, however, using path dependence thought for organization studies fails to recognize the fact that this conception has been developed in the context of markets, which particularly implies autonomous actors and decentralized or atomized decision making. Translated into organizational modes, this would come close to a completely decentralized model, where evolutionary processes set the agenda. The logic of a hierarchical organization differs markedly. Actors are not independent; rather, they work under the regime of formal power. Organizations are constituted by (the obedience to) hierarchical order. The formal organizational structure is designed to execute upper level decisions, and hence by its very nature distributes power unequally among its members (to varying degrees depending on the design philosophy). Authorities are entitled to enforce prescribed behavior and programs. Organizational members are expected to obey (Weber 2009), or risk sanctions. By implication (at least in principle), disliked evolutionary dynamics can be suppressed or crowded out by 
order. Therefore, the fundamental question arises whether evolutionary, selfreinforcing processes can actually take over the regime in formal organizations against the hierarchical order.

To our knowledge, this crucial question of the possible overruling power of the hierarchical imperative has not yet been thoroughly examined. It is still to be explored whether self-reinforcing mechanisms can spread in hierarchical organizations in the same way as in decentralized symmetrical settings, or whether their dynamics - if unwanted - can be overruled by hierarchical order. If the proposition is true that hierarchical interventions can significantly weaken, restrain, or even stop the potentially hazardous effects of self-reinforcement, then the theory of becoming locked-in within organizations would have to be reconsidered. Further, if the second proposition is true that self-reinforcing dynamics clearly overrule formal authority, then the theory of formal organizations has to be revised.

The theory of formal organization assumes formal structure as the dominant determinant of organizational behavior. This assumption is based on the legitimation of hierarchy, that is, on rational-legal authority (Weber 2009). When entering an organization, organizational members agree (by signing an employment contract) that they are willing to obey. Employers and their delegates have the overriding authority. Disobedience can be sanctioned ultimately by dismissal. These are the basic ingredients of hierarchical order, and all formal organizations still rely on them.

It is also well known, however, that there is a long tradition in organization theory to elaborate on emergent processes in organizations that often amounts to important factors in organizational life (Blau 1957; Katz 1965; Pettigrew 1971; Misztal 2002; Hernes 2014). Take pervasive features such as organizational culture, spontaneous cooperation, and micropolitics. Very early work of Selznick (1948) highlighted already the relevance of informal structures. It was suggested that organizations could be conceived of as "cooperative systems" (Selznick 1948: 27). Further, Meyer and Rowan (1977) cast doubts on the assumption that organizational actions actually conform to the espoused behavior, urging a sharp distinction between formal structure as legitimating facades and rules that are actually followed. Additionally, research on the dynamics of organizational subcultures (Sackmann 1992; Spiegel et al. 2017) highlights the significance of heterogeneous implicit assumptions for organizational coherence beyond hierarchical coordination. In sum, many research findings underscore the importance of emergent processes and evolving practices in organizations. However, in most cases this occurs without examining the contradiction to the logic of hierarchical control. Path dependence and the idea of unfolding self-reinforcing processes in organizations are another stream in this research on emergent dynamics in organizations.

By implication, applying the theory of path dependence to hierarchies stands between two conflicting views: the first being the predominance of hierarchical control building on the employers' order, and the second being the regime of emergent (and in the case of path dependence, self-reinforcing) processes. This may be seen as not just two different perspectives, but rather, as a veritable struggle between two rivaling forces, raising the question: which one is likely to win? Or to put it differently: In the case of conflict, are self-reinforcing processes strong enough to overrule hierarchical power and control? This question has far-reaching implications 
for the debate on the importance of explanations based on path dependence in organizations, or more broadly, on self-reinforcing dynamics. Therefore, it seems worthwhile to elaborate on the struggle between the two rivaling forces of selfreinforcing processes and hierarchical order. Thus, our research question is as follows: Can a strong hierarchy hold back self-reinforcing processes? Or to put it differently: Can hierarchical order suppress (over time) self-reinforcing path building?

From a methodological point of view, it is extremely challenging to study the effectiveness of two countervailing forces over an extended period. Empirical, longitudinal studies of such controversial developments require a long observation time, which can be extremely difficult to realize for several reasons. A retrospective, recapitulation of the processes, as an alternative, is troubled by many biases (Langley 2009). We suggest taking another approach to study these processes. As will be demonstrated in detail below, agent-based simulation offers a promising design to represent the logic of the rivaling forces and observe (in the stylized world of a model) their effects in organizations over a considerable number of time-periods.

Our paper proceeds as follows: First, we clarify the notion of path dependence, its major phases, and the regime of self-reinforcing dynamics. Next, we discuss the bases of hierarchical order, which from our research perspective is conceived as a countervailing power. For the remainder of the paper, we study these two rivaling forces in a context that is particularly important for understanding the dynamics of organizational path dependence (David 1994): the process of adopting or rejecting new institutional solutions in an established organization or a cluster of organizational rules. After operationalizing the central notions, we develop a simple simulation model of institutional development in systems. Applying the "building block method" suggested by Davis et al. (2007), we extend this simple model to a more comprehensive model of organizational path dependence or-as we call itthe non-hierarchical model. This enables us to examine whether, under the premises of the model, the self-reinforcing processes actually lead into a lock-in. In the next step, we extend our model, introducing hierarchical power as a counterpart. Because we are interested in the comparative long-term effect of the two potentially rivaling regimes, we explore whether path dependence and lock-ins can also occur in the hierarchical world, or whether the hierarchical order is strong enough to resist against unwanted, self-reinforcing dynamics. To conclude, findings indicate that both regimes represent strong forces. The temporal order proved important: At the beginning, the formal rules/order seem to dominate but after a while, the emergent dynamics of self-reinforcing processes come more and more to the fore. Finally, under special conditions they proved stronger than the hierarchical order. In the final section, we discuss the theoretical and practical implications of our findings.

\section{Theoretical background}

\subsection{Organizational path dependence}

Fundamentally, path dependence thought highlights the historicity of organizational processes: initial decisions in the past increasingly restrain present and future 
choices, thereby challenging the ahistorical rational choice view. Paul David (1985) established the discussion on path dependence from an economic perspective. Within his historical studies, he explored the puzzling persistence of the QWERTY keyboard technology, investigating why an inferior standard has been adhered for more than 100 years, despite superior technological innovations being available at different points in time (see for a critique Liebowitz and Margolis 1990, 2013). His exploration of this lock-in surfaced as major drivers underlying self-reinforcing processes, which eventually led into this long-term domination of an inferior technological standard. Other cases provided further evidence of a surprising persistence of inferior technologies in various technology markets (David and Bunn 1988; Cusumano et al. 1992; Cowan 1990; Cowan and Gunby 1996; Fouquet 2016). When formalizing the theory of path dependence, the existence of increasing returns proved to be crucial for explaining lock-ins (Arthur 1989, 1994).

Path-dependent processes have been characterized by non-predictability, nonergodicity, inflexibility, and potential inefficiency (Arthur 1989, 1990; David 2001; Pierson 2000). By implication, the state of path dependence is not predictable at the beginning; initially, various alternatives are possible (multiple equilibria). In case of operating self-reinforcing effects, a first decision advanced by a small, mostly random event becomes prominent. The initially broad scope of choice increasingly narrows, and the self-reinforcing process eventually leads into a lock-in (which may amount to a dysfunctional trap). Accordingly, organizational path dependence can be conceptualized as the outcome of a dynamic process that is driven by one or more self-reinforcing mechanisms. It proved useful to differentiate this process into three distinct phases based on varying regimes: pre-formation, formation, and lockin (Sydow et al. 2009):

Phase I is characterized by contingency. Different futures are possible and choice is largely unrestricted. Often a "small event" (for example, sudden time pressure, spontaneous preferences for one solution, or immediate availability) favors one of the various solutions or options. If this decision triggers (unforeseen) selfreinforcing dynamics or positive feedback, a process of narrowing the scope begins.

Phase II starts in the case of continued positive feedback. Increasing returns make the chosen solution in future decision processes ever more attractive, diminishing the probability of choosing other solutions, thereby constituting the evolvement of an organizational path (Arthur 1989; Sydow et al. 2009). At the same time, the reversibility of the evolving solution pattern decreases.

With the transition to Phase III, the diminishing window of opportunities eventually closes, leaving only one feasible solution (lock-in). The choices replicate the same solution. Other alternatives have diminished (as in the case of QWERTY) or are no longer attainable, even in cases where better solutions (such as strategic or technological alternatives) are in principle available (inefficiency).

In this framework, the existence of self-reinforcing mechanisms is a necessary condition for unfolding the narrowing dynamics that results in path dependence. In Phase II, agents enjoy the benefits of positive feedback and by doing so they increasingly commit (unconsciously) to path building. The diminishing variety and rising limitation of choices are (often overlooked) collateral side effects of this process. Path dependence research has hallmarked self-reinforcing mechanisms that 
drive path emerging processes (Katz and Shapiro 1985; Schreyögg and Sydow 2011; Dobusch and Schüßler 2013; Arthur 2018). Various forms of self-reinforcing mechanisms can be distinguished. From an institutional perspective, two mechanisms deserve particular attention: The coordination effect and the logic of complementarities. The coordination effect (North 1990) refers to the increasing benefits of coordinated behavior. The more the agents adopt a specific institution the better their behavior becomes expectable for others, which in turn makes coordination among these agents easier and more efficient. Thus, shared rules contribute to the anticipation of agents' behavior; reactions become foreseeable and, as a result, uncertainty in transactions and coordination costs can be reduced. From an agent's point of view, the attractiveness of adopting an institution rises with its spread.

Together with coordination effects, complementarities are at the heart of selfreinforcing processes driving the process of institutional development. In our study, we focus on this mechanism which builds on the logic of the coordination effect; it can, therefore, be identified as a combined effect. Formally, activities can be defined as complements if "doing one of them increases the returns to doing the others" (Milgrom and Roberts 1995: 181). For a better understanding of the dynamics of complementarities of institutions we adopt David's view (1994). He argues that two (or more) institutions are complementary to one another when the existence of one institution makes the adoption of other institution(s) more attractive for the decision makers within the system, and vice versa. Building on the notion of a well-tuned cluster of different institutions, David (1994) argues that in dynamic and complex environments new problems emerge all the time, making it necessary to develop and adopt new institutions, adding them to the existing cluster of institutions. Among alternative institutional solutions designed to solve the new problem at hand, actors favor those institutions that are more compatible with already existing institutions. Complementary choices allow misfit costs (those resulting from integrating less compatible misfitting institutions into the existing cluster of institutions) to be avoided (for a similar conception of consumer misfit costs see Viswanathan 2005). The attempt to avoid misfit costs (or to earn benefits from fitting) means to favor the integration of new institutions that are highly compatible with the cluster of existing institutions (see also Milgrom and Roberts 1995: 190); these are coherent because of the coordination effect depicted above. Whenever a new institution arrives, actors will evaluate them in terms of consistency (complementarity) with the existing institutional cluster. This means that due to misfit costs, a path or a trajectory emerges and becomes established along complementary new institutions-thereby the cluster becomes ever denser (Kremser and Schreyögg 2016). As a result, institutional clusters in their specific arrangement become persistent or even lockedin. This argument for institutional complementarity later builds the basis for the path dependence modeling in our simulation as illustrated in Fig. 1.

\subsection{Hierarchy and order}

This analysis of organizational clusters or sets of rules becoming path-dependent builds on the predominance of emergent processes in organizations. In a way, it is 
Fig. 1 Self-reinforcing feedback loop of institutional complementarities
New institutional solutions in accordance with existing institutions are favored to avoid misfit costs

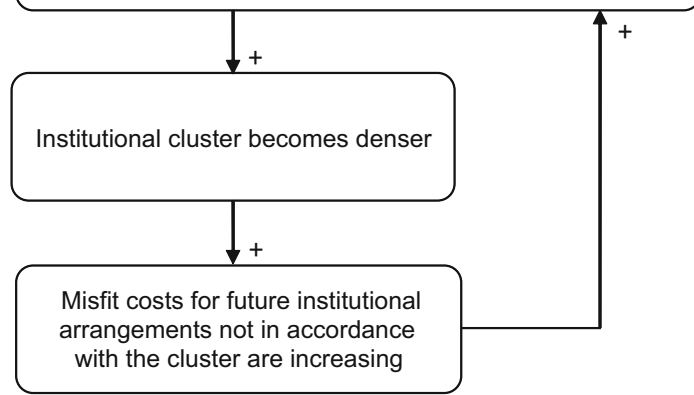

an analysis of unintended and ultimately unwanted consequences in organizations. Organizational members are implicitly conceived as independent actors that can decide whether they are willing to conform to a new rule or routine. Rule-guided behavior is driven by mutual adjustments. Rules/institutions or rule sets are accepted because of positive coordination effects or, in the case of additional new rules, they help avoiding misfit costs. This is rather an emancipated view of organizational life referring to independent decentralized decision making and free flowing feedback processes across all agents. This raises the intriguing question of whether these dynamics actually apply to organizations building on a strict hierarchical order. ${ }^{1}$ All classical studies, beginning with Max Weber (2009), point to hierarchical authority as the essential characteristic of formal (bureaucratic) organizations (Blau 1957; Blau and Scott 1962). Hierarchies are based on the "one man, one boss" principle to guarantee the unity of command, resulting in a consistent chain of command. By implication, power is unequally distributed. The span of control is a crucial issue in designing organizational hierarchies. The span of control refers to the number of staff who report to a manager. The average span of control shapes the steepness of the hierarchy. Higher average spans of control mean fewer layers of hierarchy; lower spans mean more layers and taller hierarchies. Authorities define rules and make provisions to guarantee the fulfilments of the ordered rules. The underlying basis is "rational-legal authority" (Weber 2009) and the overriding authority of employers, expressly consented to by organizational members when signing their employment contracts. It is unnecessary to restate the theory of formal organizations and its differentiations in more detail here; it has become common knowledge and broadly accepted for understanding of how organizations work in theory and practice.

The conception of a formal hierarchy sharply deviates from the idea of predominant emergent phenomena including organizational path dependence; a world of emergent unwanted forces that determines organizational behavior does not conform to the idea of bureaucratic authority and formal control. Following this

\footnotetext{
1 The authors are indebted to Pamela Tolbert for asking insistently this question and thereby motivating this paper.
} 
line of reasoning, the theory of organizational path dependence, and more generally theories of self-reinforcing processes, raise an intriguing question: Are unwanted path-building processes powerful enough to overrule the prescriptions of the formal system? Or to put it differently: Can formal authorities actually suppress pathbuilding processes, in particular the dynamics of self-reinforcing processes, when these do not conform to their objectives? This is a challenging question that has not yet, to our best knowledge, been addressed in the literature on path dependence and self-reinforcing processes. The countervailing power of hierarchical authority has remained a blind spot. This is a crucial question because it refers to the essentials of organizational path dependence, and more generally self-reinforcing thought. The conception of organizational path dependence basically builds on the implicit assumption that self-reinforcing processes can overrule formal authority. It is also essential for the theory of formal authority, which implicitly assumes that hierarchical order can overrule emergent processes (for example path dependence or other self-reinforcing dynamics). In other words, there are rivaling forces; it is not clear and it cannot be derived from literature a priori, which is stronger. Therefore, the research question proposed is as follows: Can hierarchical order suppress selfreinforcing processes and path dependence? In the following sections of this paper, we aim to provide an answer.

\section{Methodological remarks}

Examining the research question empirically meets a number of obstacles. First, it is difficult to find a research site that actually allows an observation of both countervailing processes. Furthermore, it is very difficult to identify path-building processes at their inception. The starting point is conceived as a random "small event" with far reaching consequences - an idea derived from chaos theory and the so-called butterfly effect (Davies 2018). Therefore, in most cases, path analyses are conducted on an ex-post basis. Second, a longitudinal design is necessary to observe the struggle between the two forces; it is unclear from the outset how long the struggle might take until a result is reached-it might take years. Conversely, retrospective designs are also affected by many problems (Langley 2009), in particular in cases where the time span covers a longer period, for example more than 10 years. As a conclusion, conventional methods do not easily apply in this instance. We think, however, computer simulation offers a promising alternative. Admittedly, this does represent a stylized method; however, it enables intricate problems in interactive processes to be addressed.

There is broad agreement that, "simulation is particularly useful when the theoretical focus is longitudinal, nonlinear, or processual, or when empirical data are challenging to obtain" (Davis et al. 2007, p. 481; similarly, Harrison et al. 2007). In particular, where the aim is to examine the development of institutions in organizations and disclose path dependencies and countervailing forces, simulation provides a comprehensive platform for studying such complex interactive effects. In simulation research (as a basic requirement) a formal model encompassing the suggested relationships has to be developed and translated into computer code; it 
can be run many times to observe the developments of the system. For our research question, "agent-based modeling" seems to be the most appropriate approach (Macal and North 2010; Farmer and Foley 2009).

An agent-based model is advantageous to other conceivable alternatives (for example, system dynamics) because it is less aggregated and thus strikes a more meaningful balance between simplicity and verisimilitude. Regarding the research question at hand, it permits the investigation of thousands of heterogeneous organizational members (agents) framed by different types of hierarchy. This allows for a more grounded representation of decision-making behavior and the study of the emergent, organizational-scale results of complex micro-level actions and interactions.

In our simulation model, we proceed sequentially. We first specify the utility function of actors or organizational members based on characteristics of complementarity effects and their functioning in organizations. We then develop a model to observe the building of organizational path dependence and lock-in. In the next step, we include hierarchical order (as a rivaling organizational force) into the model. For this purpose, we model hierarchical power and its interaction with complementarity effects. Finally, to answer our research question, we aim to observe whether hierarchical effects can suppress self-reinforcing processes of complementarities and the emergence of lock-in.

\section{Modeling}

\subsection{Actor as basic element}

The major aim of this section is to model agents' behavior based on complementarities and its consequences for organizational path dependence. We start by conceptualizing organizations as social systems of interdependent agents and choices (Siggelkow 2011). In the model, the system consists of 1000 agents (individuals), required to choose whether to comply with one of two possible institutional solutions ( $A$ or $B$ ) developed as an answer to a new emerging coordination problem (David 1994). In accordance with other models of organizational choice (see for instance Siggelkow and Rivkin 2005, and Hodgson and Knudsen 2004), the two solutions studied are considered exclusive, offering incongruent solutions to the same problem (think of $A$ as proceeding along the firstin-first-out principle, and $B$ as proceeding according to urgency). Each agent $i$ has exactly one attribute, which is the adoption of one of the two contradicting solutions $A$ and $B$.

The main challenge in modeling a multi-level design problem is the interdependence of interactions. On a micro level, agents' behavior reflects individual circumstances (such as individual preferences) but is influenced at the same time by macro level dynamics. In the particular context of our model, the latter are characterized by the diffusion rates of the two rivaling solutions previously mentioned (or more formally, the actual density of the rivaling institutional clusters). The macro-level state of the system builds on micro-level decisions of 
individual agents and is defined by the number of agents who adopt the solution A or $B$. Therefore, both levels mutually influence each other at all times; agent-based simulation is a well-suited and proven method for investigating such processual interdependencies (e.g. Rivkin and Siggelkow 2003; Siggelkow and Rivkin 2006: 782).

In the following sections, we develop simulation models according to our research question, the juxtaposition of path dynamics in both a hierarchy-free and an explicitly hierarchical institution. First (Sect. 4.2), we study the path dynamics in a hierarchy-free setting with a model based on the self-reinforcing mechanism of complementarities (including the coordination effect). Next (Sect. 4.3), we develop a model for the hierarchy based on order and obedience; thereafter this will be included into the non-hierarchical model.

To address our questions a model is required that describes the decision making of an individual agent. It further requires that agent interactions with the macro state of the organizational system are specified (For example, "What are the implications of different organizational states for individual decision making?") and outcomes of individual decision making (in terms of the density of the two rivaling institutional clusters) are measured.

Individual agent's utility function: The utility function that determines the agent's decision is at the heart of the model. As the model is customized to an organizational setting, we need to specify the motivation and expectations that lead individuals to engage in the attainment of specific goals. To do so, we adopted a simplified version of a well-known and widely used motivation theory for this purpose: The Expectancy-Valence-Theory of Motivation (Vroom 1964). This theory is pertinent in explaining cognitive choice and decision making for individuals in an organizational context. Furthermore, the main idea of the theory-employees' choice between alternatives also depends on the organization's ability to link organizational and personal goals_-is intuitive and yet builds on a complex, multilevel argument. Finally, its mathematical representation makes it a suitable base for simulation modeling, allowing a transparent representation of the competing logics.

In its most basic formulation, the theory states that an individual's force to act towards a specific outcome $j=1, \ldots, n$ is a product (multiplicative) of valence (anticipated satisfaction through outcome $j$ ) and expectancy (the belief that effort will actually lead to outcome $j$ ). According to the theory, after comparing the available alternatives the individual chooses the alternative that has the strongest force to act. We proceed with a simplified model here where the individual agents' force to act $\mathrm{FTA}_{j}$ for all alternative outcomes $j$ is determined according to the following:

$$
\mathrm{FTA}_{j}=E_{j} \times V_{j}
$$

where $E_{j} \in[0,1]$ denotes the agent's expectancy for alternative $j$ and $V_{j}$ is the valence (in our model always positive), with $V_{j} \geq 0$.

Expectancy: The expectancy $E_{j}$ measures the belief concerning the likelihood that outcome $j$ can be realized by the efforts. According to path dependence theory, initial choices should be triggered by a random "small event" (David 1985; Arthur 1990), while this accidental effect should diminish when the process unfolds. 
Therefore, small events are modeled by randomizing the expectancy $E_{j}$, meaning that there are different estimates about the expectancies across actors, which are not initially correlated, for example because of high uncertainties or strong arguments for both institutions.

Valence: The variable valence represents a measure of attractiveness of an organizational goal (first level outcome $j$ ) that depends on preferences for different personal goals (second-level outcomes such as income or social acceptance) and perceived instrumentality, that is, the belief that performance will actually lead to promised rewards. To keep the complexity of the model manageable, we suggest considering the perceived instrumentality of solutions as given and fixed. This implies neutralizing the instrumentality so that the valence (anticipated satisfaction of individual needs) for the agent is identical to the anticipated goal attainment. Furthermore, we reduce the scope of individual goals (second level outcomes) to just one goal, benefitting from complementarities. We assume a scenario of positive complementarities where the agent's individual valence $V_{j}$ increases with the density of the according institutional cluster. In doing so, we build as already stated on David (1994), who assumes that decision makers favor a new institutional option compatible with the established cluster of institutions to avoid misfit costs (earn benefits). Similar to Schneider (2014), we use a non-linear (exponential) evaluation function. To that end, we introduce a strictly monotonically increasing function that determines the value of $V_{j}$ for $M \in\{A, B\}$ as follows:

$$
f_{M, c}(x)=\mathrm{e}^{m \times c \times x \times 1.5},
$$

where $x \in[-1,1]$ denotes the density of the corresponding institutional clusters, $c \in$ $[0,1]$ is the strength of the complementary feedback, and $m=1$ for $M=A$ and $m=-1$ for $M=B$, respectively. The intuition underlying the function hinges on $c$. A value of $c=0$ means that an increase in diffusion rate does not affect the corresponding cluster's density at all, whereas $c=1$ means that an increase in cluster density increases the strength of the complementary feedback to its maximum, that is, $\mathrm{e}^{(-) 1.5 x}$. To the extent that $c$ exceeds zero, $c$ regulates the impact of a higher diffusion rate of the focal institution on the institutional cluster's density. Put differently, and as illustrated in Fig. 1, $c$ regulates the degree of complementarity of a new institution with the existing institutional cluster. Due to misfit costs, a path is established along complementary institutions-thereby the cluster becomes ever denser.

The density of the corresponding institutional cluster $x$ represents the individual agents' decisions aggregated to the macro state of the organizational system. The density thus characterizes the macro state of the organizational system. For reasons of normalization and consistency with prior studies (Weidlich and Haag 1983; see also Gilbert and Troitzsch 2005: 102ff.), we adopt a condensed measure for the diffusion of the two exclusive solutions in a system. In particular, we define $x$ to be the measure of the density of the institutional clusters with $x=2 \times d_{A}-1$ where $d_{A}$ refers to the diffusion rate of solution $A$. From this it follows that $x \in[-1,1]$ where $x=1$ means that when $x$ approaches the value of $1(-1)$, the corresponding system behavior approaches a diffusion rate of $100 \%$ for $A(B)$, meaning that all 
individuals have complied with the institutional solution compatible with the denser cluster.

Taken together, an agent's force to act $\left(\mathrm{FTA}_{j}\right)$ is represented as follows:

$$
\mathrm{FTA}_{j}=E_{j} \times \mathrm{e}^{m \times c \times x \times 1.5}
$$

For the two alternatives $A$ and $B$, individuals would decide to adopt $A$ if $\mathrm{FTA}_{1}>\mathrm{FTA}_{2}$ and $B$ if $\mathrm{FTA}_{1}<\mathrm{FTA}_{2}$.

\subsection{Modeling the non-hierarchical setting}

Building on this simple model of preferences and complementarity effects in organizations, as a first step we set out to observe path development in the hierarchy-free organizational environment. First, we observed the dynamics of the simple cases of a hierarchy-free organizational setting without complementarity effects $(c=0)$, which-according to the theory of path dependence-should not result in a lock-in ${ }^{2}$ because there is no self-reinforcement. Second, we studied the other extreme, that is a setting with the highest possible degree of complementarity effects $(c=1)$, expected to bring about a path dependence due to forceful selfreinforcement.

Model implementation and simulation setup: We implemented the model using the Netlogo 5.x simulation environment. We did so as it provides an intuitive user interface and is a widespread tool among a large user community, allowing rapid feedback and experimentation.

We applied a discrete timeline, where time is counted in a unit called "ticks". This approach aptly captures how patterns of behavior unfold over a period where it is relatively unimportant how long the interval between each period may be. In each tick, each agent decides (according to its force to act) whether to adopt a behavior compliant with $A$ or $B$, as represented in Eq. (3).

Because our research scope was longitudinal, we could apply the Monte Carlo method that allows us to rely on repeated random sampling to obtain numerical results for a large number of artificial experiments (the following results are aggregated over 1000 independent runs). Results stated in this paper were obtained with equal initial density for each cluster, which is $x=0$ at the beginning of each simulation run (no sponsoring/upfront biases).

\subsection{Modeling the hierarchical setting}

We proceeded by including hierarchy into our model to study the authority effect and the rivalry between self-reinforcing processes and formal hierarchy. We thereby addressed the possibility that formal authority or a hierarchical organizational design might control the diffusion processes of institutions within organizations. In

\footnotetext{
${ }^{2}$ For the purpose of this simulation, we defined a lock-in state as a situation in which no meaningful variation in outcomes occurred over a prolonged period, i.e. one institutional logic is dominating the system with a diffusion rate of more than $95 \%$ for a period of at least 500 ticks.
} 
an attempt to embrace this rivalry, the notion of organizational hierarchy as a countervailing force was added to the initial model.

To specify the existence of formal authority, we assigned a superior to each agent in the system. Hereafter, we rely on span of control (span) as one important feature of organizational hierarchy (see our explanations above). It can be seen as a powerful means of ensuring proper coordination and a sense of accountability among employees, possibly countervailing individual preferences. Varying the span of control allowed us to examine different organizational designs from steep hierarchies with a small span of control to organizations with flat hierarchies. ${ }^{3}$

In the simple model, agents decided on new institutional options exclusively based on calculating misfit costs arising from institutional clusters. Building on our notion of organizational hierarchy as authority imposed by superiors, we could next introduce another competing variable influencing the individual decision-making process, referred to as 'leadership impact' (li). This variable represents explicit orders from superiors as well as more implicit elements, as individuals in organizations aim to meet the expectations of their official superiors even if no explicit order exists. The individual's decisions are thus dependent on complementary feedback, and leadership impact of their superiors (and also random small events). The two factors are considered as competing. To examine our major research question whether the influence of self-reinforcing processes is higher than the hierarchical influence, we developed the following model:

In each tick, one agent after another selects either $A$ or $B$ according to the following decision rule:

Behave in accordance with $A$ if and only if $\operatorname{FTA}_{A}(x, y)>\operatorname{FTA}_{B}(x, y)$ and

$B$ if and only if $\operatorname{FTA}_{B}(x, y)>\operatorname{FTA}_{A}(x, y)$ and

if $\operatorname{FTA}_{A}(x, y)=\mathrm{FTA}_{B}(x, y)$ do not alter the previous behavior.

$\operatorname{FTA}_{A}(x, y)$ and $\operatorname{FTA}_{B}(x, y)$ are specified as follows: $\mathrm{FTA}_{A}(x, y)=E_{1} \times\left[f_{A, c}(-\right.$ $x)+i(y) \times l i]$ and $\mathrm{FTA}_{B}(x, y)=E_{2} \times\left[f_{B, c}(x)+i(y) \times l i\right]$ with $f_{M, c}(-$ $x):=e^{m \times c \times x \times 1.5}$ and fixed $c \in[0,1] ; E_{1}, E_{2}$ uniformly at random $\in[0,1]$; $M \in\{A, B\} ; m=1$ for $f_{A, c}(x) ; m=-1$ for $f_{B, c}(x) ; l i$ fixed $\in \mathrm{R}^{+;} i(\mathrm{y}) \in\{-1,1\}$ depending on the adoption behavior of the superior. If the superior has currently adopted $A$, they influence their subordinate to also adopt $A$, so $i(y)=1$ when $\operatorname{FTA}_{A}(x$, $y)$ is calculated and $i(y)=-1$ when $\operatorname{FTA}_{B}(x, y)$. The reverse is true if the superior has currently adopted $B$. Altogether, we propose one simple yet representative hierarchical organizational design, which is visualized in Fig. 2 (in Netlogo).

This comprehensive model allows us to observe the impact of organizational hierarchy on the path-building process. After various sensitivity tests, we fixed the degree of complementarity to the maximum level $c=1$ to ensure that strong positive feedback was in place. Our goal was to examine the effect of hierarchy in organizations in general; to keep the scope, our study aims at covering different types of organizational hierarchy. We, therefore, examined different manifestations of the organizational hierarchy by varying the magnitude of leadership impact (li) and various spans of control (span) as independent variables. In this way, our model

\footnotetext{
${ }^{3}$ In the non-hierarchical model, technically spoken, the span of control would be zero. This allows the non-hierarchical model to be regarded as a benchmark.
} 
can emulate a wide range of hierarchical designs, from organizations with large control spans and authoritarian leaders to those with small control spans and less authoritarian managers.

\section{Results}

\subsection{Results for the non-hierarchical setting}

Figure 3 presents the simulation results for path building in non-hierarchical settings. As already mentioned, we differentiated between two extreme cases in terms of interpolated probability density (the ratio of cases in which the outcome occurred) of $x$ over time for complementarity $c=0$ (Fig. 3, experiment A) and $c=1$ (Fig. 3, experiment B). Without complementary effects $(c=0)$, random small events determined the initial decision. Because $t$ agents decided each tick simultaneously, the law of large numbers worked as expected, meaning the system converged to a state where both institutions were equally distributed among the agents. The density distribution of $x$ (Fig. 3, A1) peaks at $x=0$ invariant of time, indicating that the agents were not becoming bound to a dominant behavior. Instead, they relied on their personal preferences and actual circumstances (modeled as small events).

If, in contrast, a maximum degree of complementary self-reinforcement was at work $(c=1)$, we could not see any instances where both institutions remained recurrently adopted over time. Instead, as illustrated in Fig. 3, B2, over time one of the two solutions became dominant, representing the only available alternative for agents at some point. In the runs we could still see constant small deviations, because the system is stochastic and the agents could reconsider their selection in each period. Nonetheless, the probability distribution (Fig. 3, B1) indicated that the most likely outcome after 1000 periods was either domination of institutional solution $A$ or $B$.

The lock-ins in a non-hierarchical environment in Fig. 3, B1, are consistent with Arthur's (1994) deductive analysis of positive feedback processes. As the model converges in each run to one (and only one) of multiple steady-state solutions ( $A$ or $B$ ), contingent on initial conditions and driven by positive feedback, it can be understood to represent a process of path dependence. In contrast to Arthur's (1994) formal analysis, by building on a computer simulation, we were able to model the process more realistically and with less restrictive assumptions. ${ }^{4}$ In summation, in

\footnotetext{
${ }^{4}$ For instance, our agents are more heterogeneous in their preferences and decisions can be reconsidered. Similar to the Polya urn (Arthur 1994), the model builds on a time-varying, stochastic process. The outcome in experiment $1 . \mathrm{B}$ can be reduced to variations in $x$ (diffusion rate) and $E_{j}$ (expectancy; distributed at random). Here, $x_{t}$ is time-dependent and an exponential factor in $F T A_{j}$. As $x$ increases, it becomes increasingly unlikely that $E_{2} \times \mathrm{e}^{-1,5 x}>E_{1} \times \mathrm{e}^{1,5 x}$, leading to the constant reproduction of the pattern to choose $A$, or $B$ respectively. The model produces a "lock-in" in the sense that variation in $x$ is decreased to a negligible level. However, the model does not tip from a "stochastic" to a "deterministic state" (see Page 2006) as it is still possible that some agents chose the non-dominant solution, reconsidering their choices each tick. We think this is a more appropriate description of many real-world situations.
} 


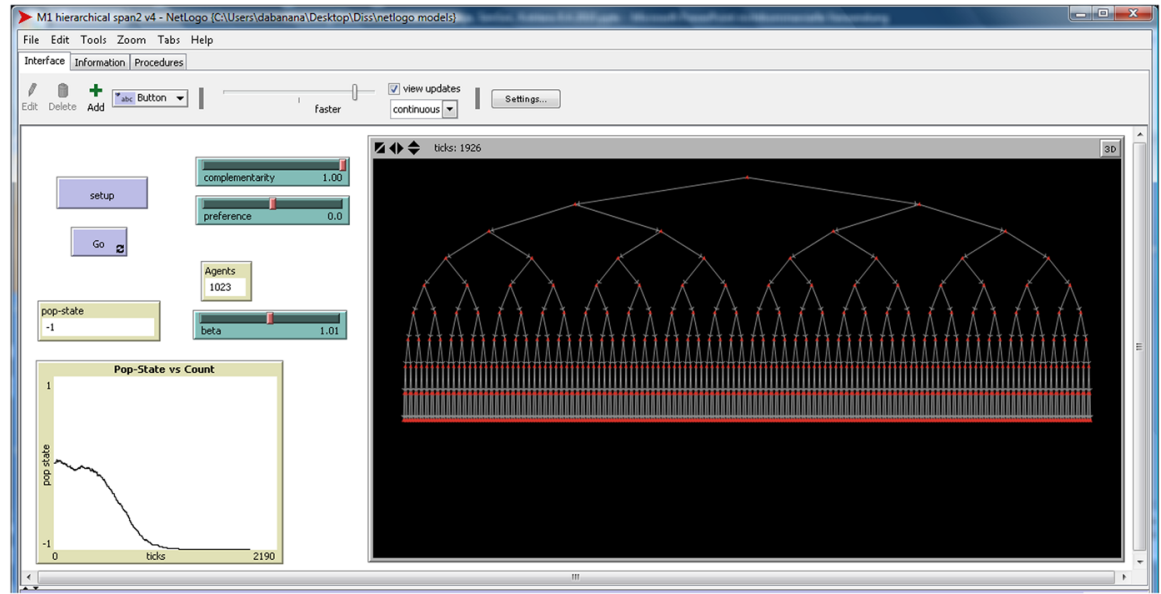

Fig. 2 A sample run of the hierarchical simulation model with span of control $=2$
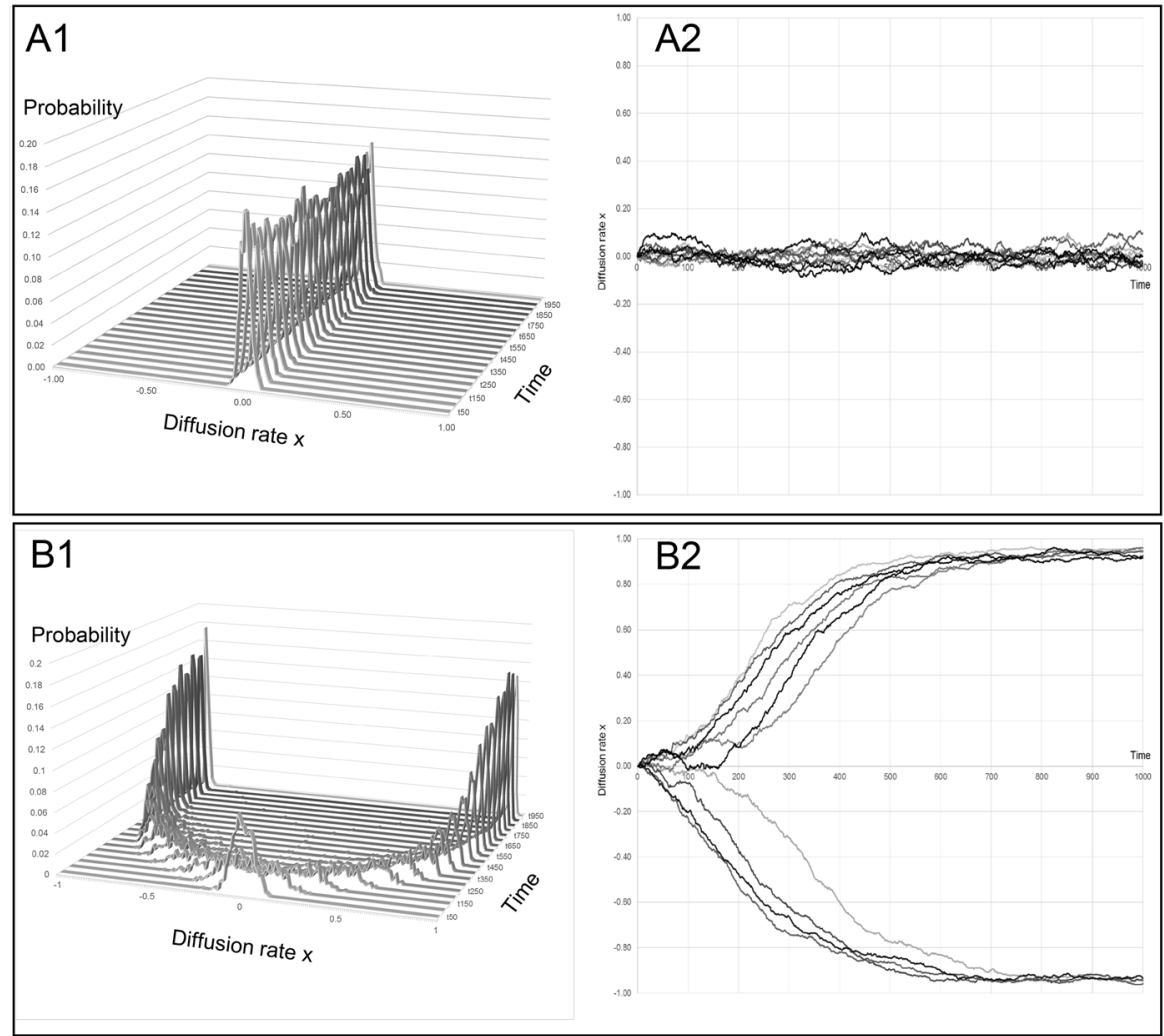

Fig. 3 Illustrations of non-hierarchical model with $c=0$ (exp. A) and $c=1$ (exp. B). Left: probability density of $x$ over time; $x$-axis: $x ; y$-axis: probability density over $x$; $z$-axis: time in ticks; Right: development of $x$ over time in ten sample simulation runs; $x$-axis: time in ticks; $y$-axis: $x$ over time 
the first situation of a non-hierarchical organizational setting, the simulation confirms expectations of path dependence. In the case of existing self-reinforcing processes (here in the form of complementarities), a dominant solution emerges early and converges, to a situation of path dependence. As already mentioned, we have modeled complementarities here (according to David 1994) as a tendency of agents to avoid misfit costs by assessing new solutions according to whether they fit into the established organization system/cluster.

In Appendix 1, we show that for the range of complementarity values $c$ between 0 and 1 , the density of the institutional cluster $(d)$ increases in $c$ and converges toward a stable value of $0<x<1$. This proves that organizations can "lock-in" toward different plateaus of density clusters. For example, complementarities may not be powerful enough, so that eventually only a stable fraction of $3 / 4$ of all employees adopts the first solution. In summary, these results demonstrate that the initial situation leads to path dependence-within the premises of the model.

To examine our research question, it is important to explore what happens if we switch to a hierarchical organizational setting: Are the dynamics of self-reinforcing processes so strong that they can even dominate a hierarchical power system? Or is the hierarchical system, building on legitimate order and obedience, able to outdo or suppress the self-reinforcing dynamics, so that the ordered solution remains intact.

\subsection{Results for the hierarchical setting}

Our simulation results indicate that both the hierarchical structure (span) and the magnitude of leadership impact (li) affect the resulting dynamics of self-reinforcing processes. We again applied the Monte Carlo method (Law 2014) to obtain results with longitudinal effects and conducted at least 100 simulation runs for each parameter combination of span and li. This method was necessary due to the stochastic properties and the sensitivity to initial conditions caused by selfreinforcing mechanisms, because the result of a single simulation run does not provide meaningful results. We first present the main results that address the question whether self-reinforcing processes can prevail in hierarchical organizations and lead to path dependence.

\subsubsection{Impact of hierarchical power on prevalence of self-reinforcing processes}

The extended simulation model allowed us to examine the implications of hierarchy on the prominence of self-reinforcing processes. We varied the span of control to ensure that our results did not depend on a specific organizational structure. While holding leadership impact constant to $l i=1$, we varied the span of control with span $\in\{2,3,5,10,32\}$. Figure 4 shows the aggregated results.

The results indicate that in spite of the existence of hierarchical power (and regardless of the variation of the span of control), we can still see a bifurcation emerging. We can interpret the results presented in Fig. 4 as follows: In circumstances where there is hierarchical power, the penetration rate of selfreinforcing processes is lower; however, over an extended period of time the 

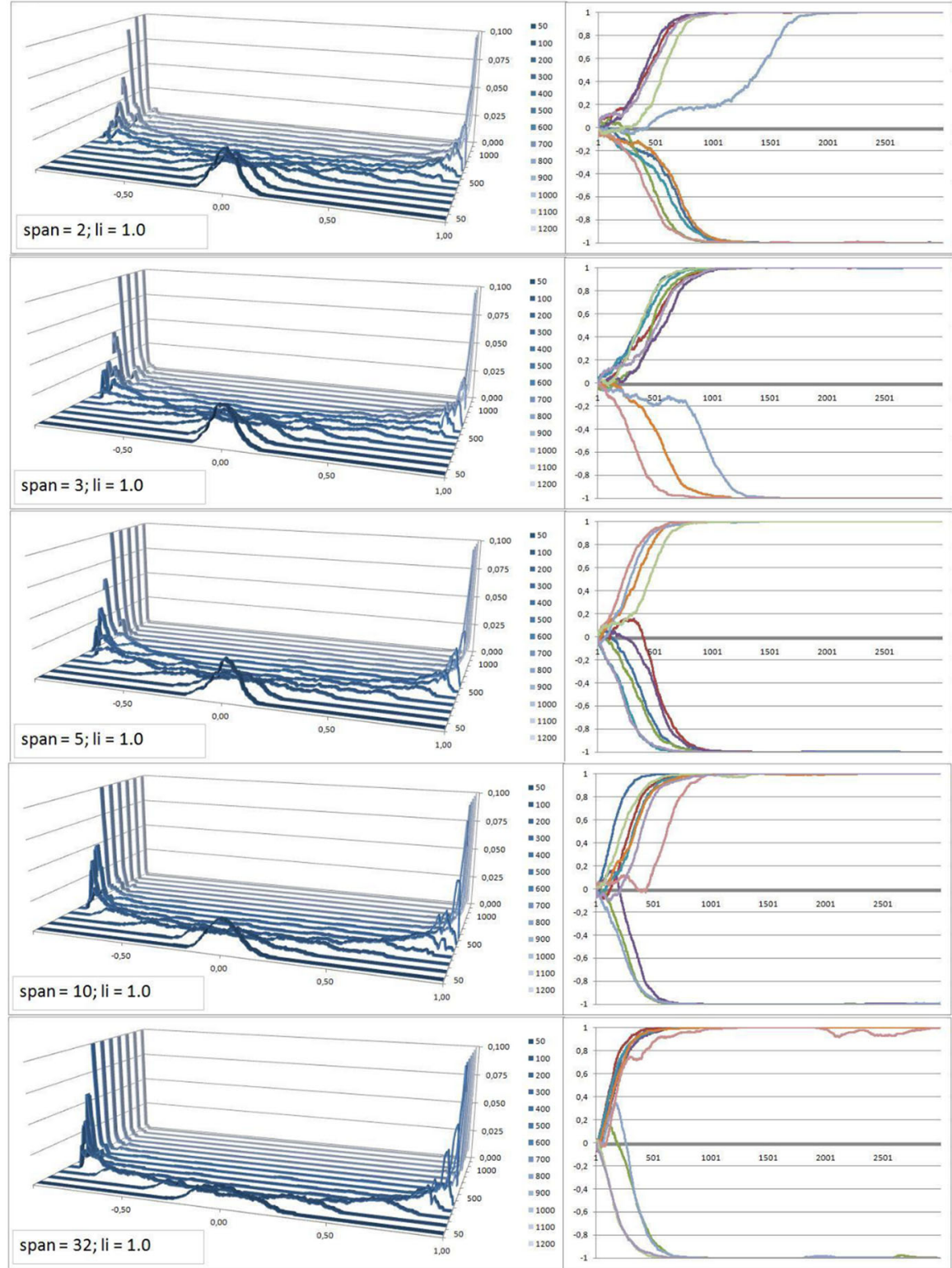

Fig. 4 Simulation results for variation in span of control with $\operatorname{span} \in\{2,3,5,10,32\}$. Left: probability density of $x$ over time; $x$-axis: $x ; y$-axis: probability density over $x$; $z$-axis: time in ticks. Right: development of $x$ over time in ten exemplary simulation runs; $x$-axis: time in ticks; $y$-axis: $x$ over time

tendency towards path dependence nevertheless prevails. Eventually, it leads to a single dominant solution over time that brings the system into a lock-in.

Contingent on increasing $l i$, we see that the bifurcation occurs later in time, but it does occur. This finding indicates that with increasing influence from supervisors in 

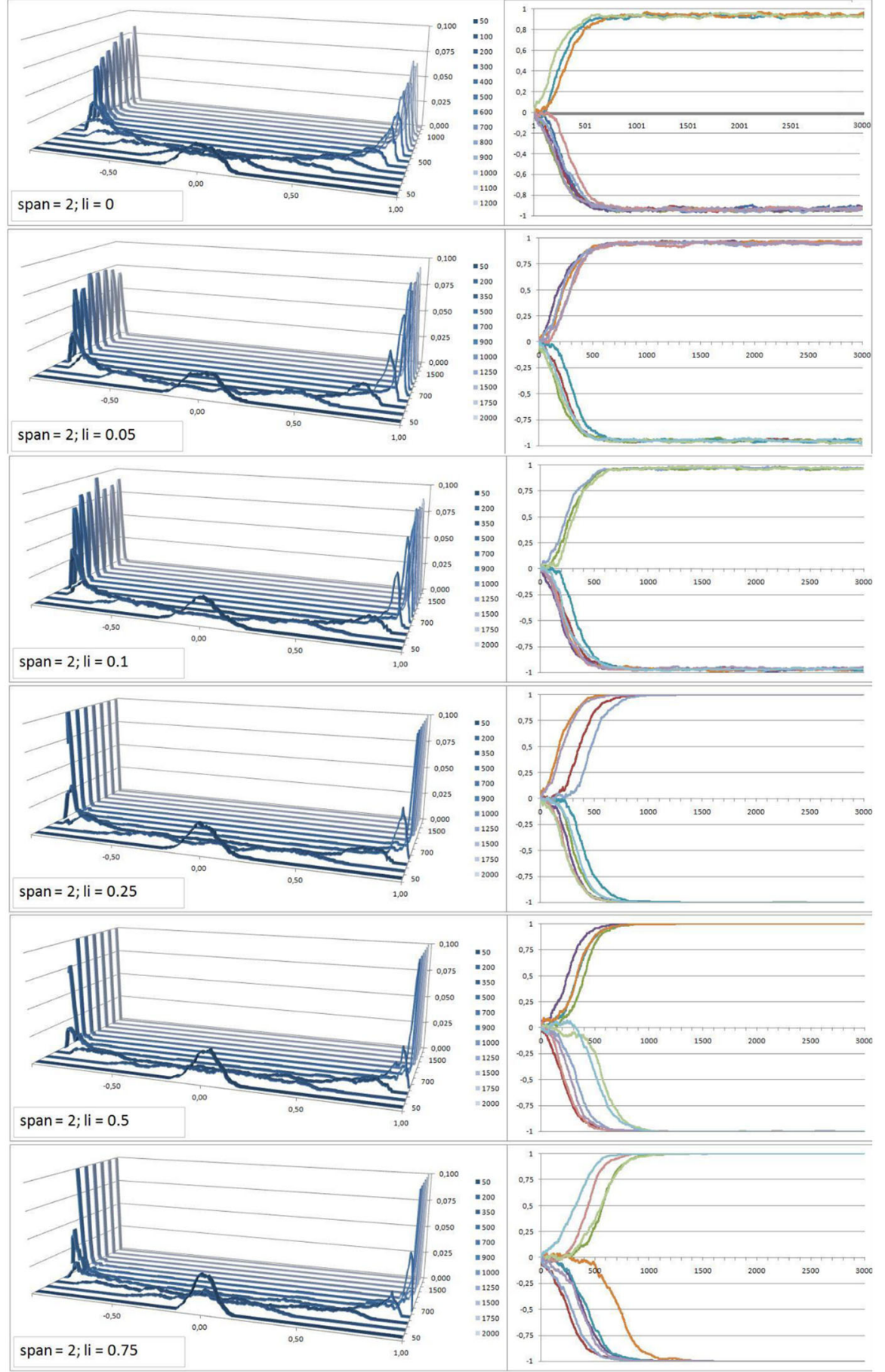
4Fig. 5 Simulation results for variation of leadership impact (li). Left: probability density of $x$ over time; $x$-axis: $x$; y-axis: probability density over $x$; $z$-axis: time in ticks; Right: development of $x$ over time in ten exemplary simulation runs; $x$-axis: time in ticks; $y$-axis: $x$ over time

a hierarchy, the second phase (the formation phase) of the path development process is prolonged. While leaders with strong power can slow down the formation of a path, ultimately the self-reinforcing logic prevails (for span $=2$ ). For the purpose of this study, the critical question remains if these results hold for a broad range of combinations of span of control and leadership impact, or only for one specifically.

This was tested. The results of the probability density of $x$ over time show that regardless of the variation in span of control, we observe a bifurcation basically similar to the results of the non-hierarchical model-in the graphical representation we see a split of the probability density landscape into two very high mountains close to +1 and -1 over time. This means that there is a path-dependent process with a dominant solution at the end of the process. Therefore, we can conclude that following the premises of our model, different hierarchical structures (at least with $l i=1$ ) cannot prevent the formation of an (unwanted) emergent path.

To assess the impact of leadership on the institutional development in organizations, we fixed span of control to span $=2$ while varying the leadership impact li. The results are presented in Fig. 5.

Table 1 indicates the probability of getting into a lock-in situation within the first 6000 ticks. We can see that lock-in situations occurred for a broad range of parameter combinations. Except for span $=2$ and $l i>3.0$, in a small number of cases we could not observe a lock-in developing, that is within the first 6000 ticks no lock-in occurred with a probability of $2 \%$. It is possible, however, that these $2 \%$ of cases become path-dependent and locked-in later in the process-it might be that it merely takes more time.

Overall, the results within our stylized framework confirm that self-reinforcing mechanisms proved to be more dominant than the hierarchical features in organizations and that neither variation of hierarchical structures (different spans of control) nor strong leadership (high leadership impact), as modeled here, prevents an organization from experiencing path dependence and the risk of a lock-in. In the following, we present refined results regarding the process itself. In addition, we present a detailed analysis of the way organizational hierarchy affects the unfolding of path-dependent processes.

\subsubsection{More detailed results on the length of the path formation phase}

The results presented above indicate that an effective organizational hierarchy does not prevent the occurrence of (unwanted) path dependence; however, it does influence the length of the path formation phase (Phase II of our model, see Sect. 2.1). The earlier the system reaches the lock-in state, the shorter the shaping of the path (Phase II). In other words, we argue for the influence of time when approaching a lock-in as a way of considering how the hierarchy matters. Figure 6 shows the length of Phase II for all configurations of span and li. 


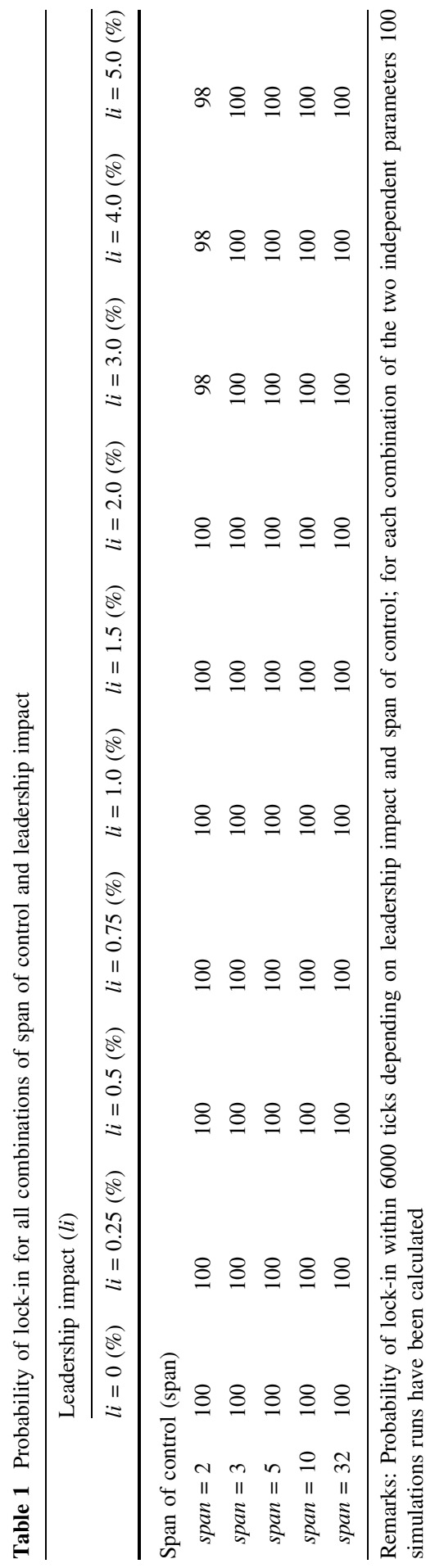




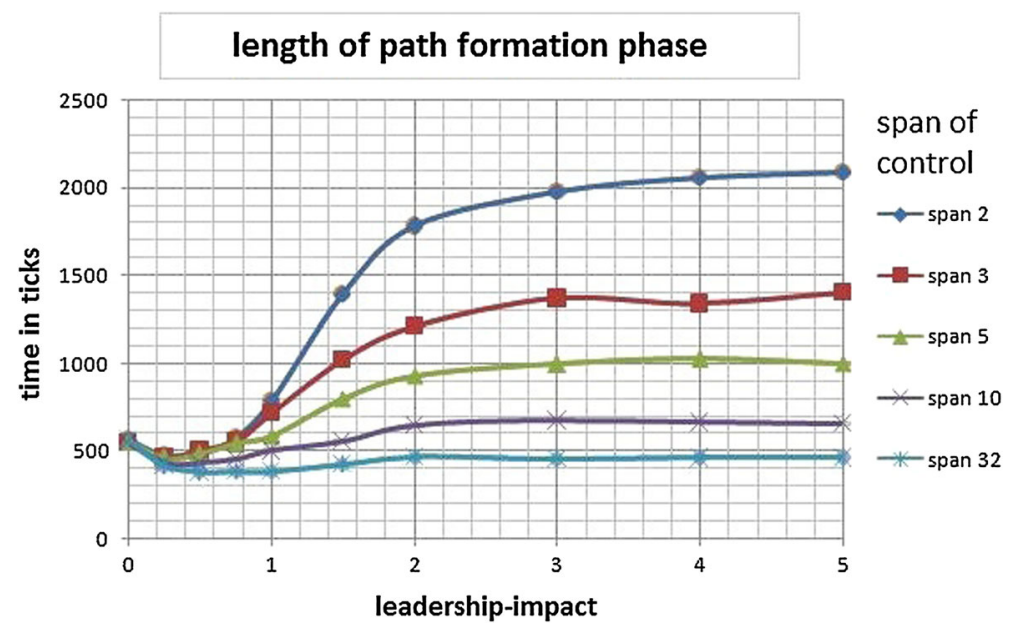

Fig. 6 Length of path formation phase dependent on variations in span of control (span) and leadership impact $(l i)$

Table $2 T$ tests on length of path formation phase

\begin{tabular}{lllll}
\hline & Span $=2$ & Span $=3$ & Span $=5$ & Span $=10$ \\
\hline$l i=0.5$ & 480.05 & 497.72 & 481.93 & 430.85 \\
$l i=5.0$ & 2057.99 & 1407.05 & 1003.37 & 654.33 \\
$t$ value & $-16.089^{* *}$ & $-12.927^{* *}$ & $-9.685^{* *}$ & $-8.064^{* *}$ \\
\hline
\end{tabular}

$* * p \leq 0.001$

First, these simulation results infer a surprising relationship: an increase in $l i$ from $l i=0$ to $l i=0.5$ actually significantly shortens the length of the path formation phase. This is surprising as we expected the impact of leadership in organizational hierarchies to be a counterforce to positive feedback mechanisms. In fact, when leadership is introduced on a low level, it seems to reinforce the positive feedback mechanisms.

As is evident from Table 2, a further increase in leadership impact results in a significant increase in the average length of the path formation phase for span $=2$, $\operatorname{span}=3$, span $=5$, and-less pronounced-for $\operatorname{span}=10$. For $\operatorname{span}=32$, we see from Fig. 6 that with the introduction of leadership (from $l i=0$ to $l i=0.5$ ) the length of path formation initially declines. In contrast to the other cases, we do not, however, see a subsequent substantial prolongation of the path formation phase for a further increase in leadership impact toward $l i=5$. In fact, for span $=32$ we can see from Fig. 6 that the path formation is even more rapid for $l i=5$ than for $l i=0$. We can, therefore, conclude that based on the premises of our model the existence of hierarchy and leadership shortens the path formation phase, when leaders are weak.

Whether strong leadership prolongs the path formation phase or not proved to be dependent on the organizational structure in our model, specifically on the span of 


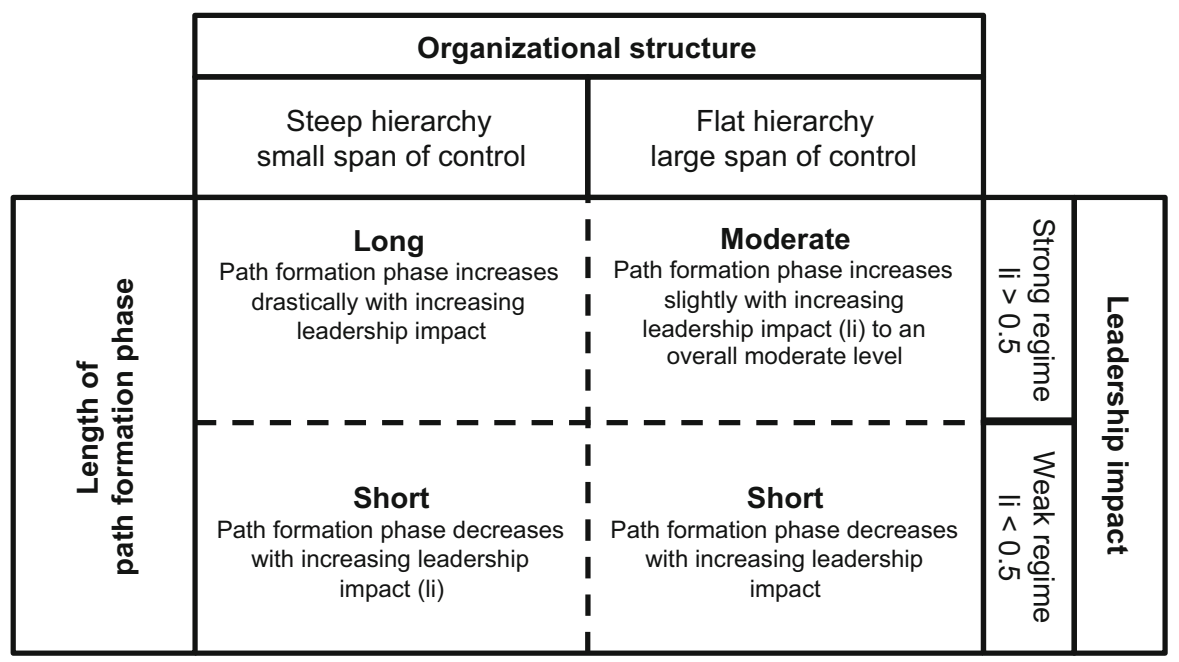

Fig. 7 Implications for the path formation phase

control. The implication is that organizations with medium or strong leaders experience a dramatic slowdown of path formation as long as they are embedded in a steep, hierarchical structure. Conversely, organizations with very flat hierarchies experience a more rapid path formation, because this model is more similar to the non-hierarchical model. The results and implications for path formation are summarized in Fig. 7.

\subsubsection{Robustness checks}

Subsequently, we conducted robustness analysis to ensure that the simulation results did not depend on specific representations of central parameters. First, we examined the sensitivity to a variation in the size of the organization (number of agents). Thereafter, we tested the effect of corrective actions, which varied the influence of leadership after path stabilization.

Sensitivity to organizational size: The results presented are based on a model with a fixed number of agents. The size could be an important impact factor. Therefore, we checked to ensure that the results hold in different types of organizations, by conducting a sensitivity analysis for smaller and larger number of agents. The results (see Appendix 2) show, however, no significant differences to the results presented here.

Corrective actions in hierarchical settings: So far, we have assumed a stable leadership influence (li) over time. However, organizations may increase or decrease their efforts to address perceived deviations from goal attainment. Organizations may use corrective actions to force a desired goal. This was checked in further simulations.

As our baseline, we took the results from Sect. 5.1, which revealed that organizations might converge and lead to a dominant (but not winners-take-all) 


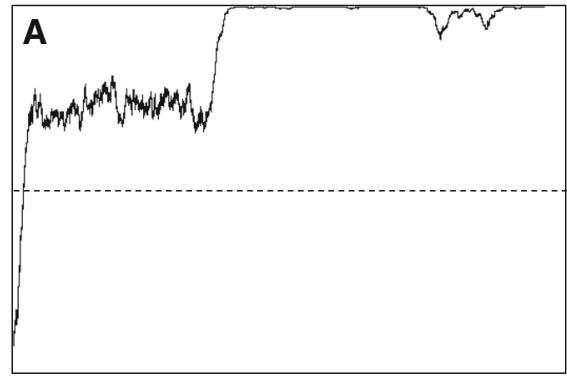

$c=0.5, l i=0.1($ after 10,000 ticks: $l i=1.0)$

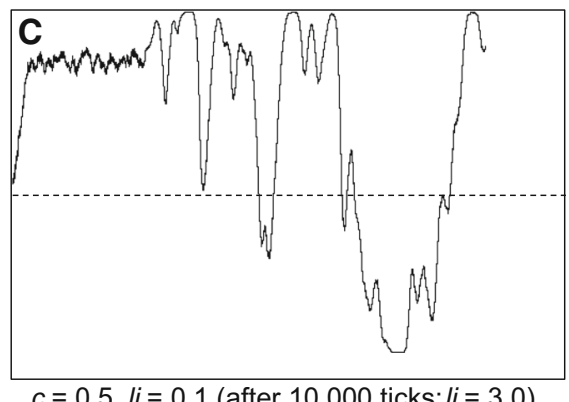

$c=0.5, l i=0.1$ (after 10,000 ticks: $l i=3.0$ )
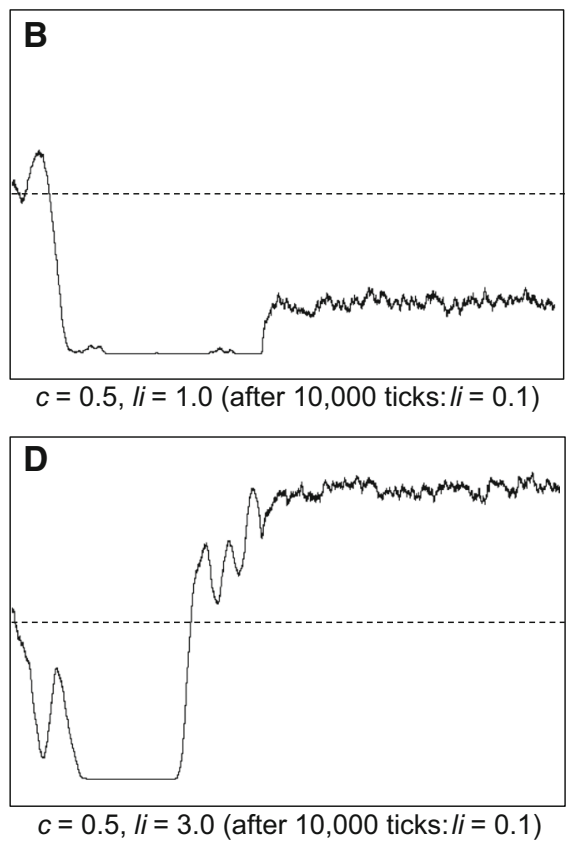

Fig. 8 Increase (left side) and decrease (right side) of leadership influence at certain time point

solution, when complementarity effects $c$ range between 0 and 1 . From this position, we introduced interventions to $l i$ given different spans of control. In particular, we started with a low/high value of $l i$, which was subsequently increased/decreased. We thereby simulated a one-time increase/decrease from level $A$ to level $B$, similar to an organization that pushes harder or less hard when there is a belief that employees increasingly "defect" (for example, by using the first-in-first-out principle instead of the management expectancy to prioritize according to urgency).

In Fig. 8, we see results from four exemplary simulations in a steep hierarchy (span of control $=2, N=1,000$ agents) where we increase/decrease $l i$ after 10,000 ticks. The strength of complementarity was set to a medium value $(c=0.5)$. In Fig. $8 \mathrm{a}$, we increased $l i$ from 0.1 to 1.0. Figure 8 indicates that after an initial consolidation phase, the results begin to stabilize at a cluster density of $x \sim 0.7$. When the intervention occurs, a jump in the graph is visible and immediately the curve flattens. After that, we can see only minor attempts to break out. In this case, the hierarchical intervention has stabilized the dominant solution. Similarly, a decrease in $l i$ can destabilize a solution, as shown in Fig. $8 \mathrm{~b}$ (where $l i$ was decreased from 1.0 to 0.1 after 1,000 ticks). In this case, the variance also increases after the decrease of the leadership influence, as expected from the previous experiment.

Figure $8 \mathrm{c}$ reveals another interesting phenomenon. With a stronger increase in $l i$ (from 0.1 to 3.0), the system becomes more erratic. As can be seen (from Fig. 8c), after the intervention the system first peaks at a cluster density of $x=1$, and then it begins to swing back and forth before it eventually flips toward the dominance of 
the opposing solution (for example, prioritize according to urgency). Increased leadership influence may tip the system. However, as is evident from Fig. 8, the system can bounce back, that is, stability is not guaranteed. In Fig. 8d, we finally see how this tendency can be used to eventually flip the system toward a desired end state. In this case and the first phase (with $l i=3.0$ ), the system circles back and forth between different options, as expected from the previous experiment. However, at the point where $l i$ is decreased considerably (to $l i=0.1$ ), the system almost immediately stabilizes at the currently dominant solution. This suggests that the timing of such a measure would be important, as with decreasing leadership influence the free flow of emergent processes begins to reignite.

A sensitivity analysis confirmed that these results were also reproducible in other hierarchical settings (such as those with larger spans of control) and for different levels of complementarity effects. In Appendix 3, we tested another intervention in which managers "punish" or "reward" employees depending on whether their actions are aligned with those of the leader.

In summary, we tested whether corrective actions deployed by hierarchies to reach goal attainment can overrule (unwanted) self-reinforcing dynamics. Based on our simulations, we can conclude that self-reinforcing dynamics remain dominant; hierarchy is able to overrule self-reinforcing dynamics in very specific constellations only. First, hierarchy dominates by upholding strong force over continued periods. Second, hierarchy is able to increase hierarchical power initially, but after a critical point it moves over (then releasing power at the right moment to give it) to the free flow of self-reinforcing processes. Yet, there is a sweet spot for such intervention: Too little increase in hierarchical power only leads to a stabilization of the existing solution. In contrast, too much hierarchical intervention can lead to a continued destabilization of the system. As it stands, these are ad hoc-differentiations; further exploration and theorizing is required. For our purposes, the major conclusion of this study is that interventions do not change the basic results of the dominance of self-reinforcing dynamics. In a small number of cases, however, interventions bring hierarchy to the fore.

\section{Discussion and conclusion}

Our research focuses on the so far neglected role of hierarchy in the development of path dependence, or more broadly, self-reinforcing dynamics. More specifically, we wanted to know whether a strong hierarchy could suppress the unfolding of (unwanted) self-reinforcing processes and thus the building of path dependence. Our simulations indicate that hierarchy in organizations can actually influence the process of complementary feedback, but only in special circumstances. Which of the competing logics and institutional solutions dominate the systems is (in the short run) dependent on random events and leadership influence, respectively, whereas the influence of hierarchical authority fades away over time, and institutional clusters become more and more dense. Additional simulations presented in Sect. 5.2.2, which varied the organizational structure and the leadership intensity, generate more or less the same results. However, they refer to restrictions regarding 
the time it takes until an institutional solution stabilizes: hierarchy can be a catalyst or inhibitor for path building. Thus, there is no unequivocal answer to the research question. In the long run path building dynamics dominate, but initially, in the short run and in certain contexts, strong leadership in combination with steep hierarchies can effectively suppress self-reinforcing processes.

A good example of these dynamics is the Bertelsmann Book Club (Schreyögg et al. 2011), where many hierarchical interventions (initiated by new CEOs) brought short-term variations; however, ultimately the path survived. Strong hierarchy proved unable to change the strategic lock-in. The owners replaced the management several times (top management alone six times from 1990 to 2007). However, all the new top managers failed to change the situation. The system 'Bertelsmann book club' reached a phase of organizational inertia or to put it differently: a lock-in. The structural change of the business environment had turned a once very successful business into an economic failure. The organization stuck so closely to the traditional business practices that any attempt to change the situation ran against an invisible brick wall. Later on, further environmental changes solved the problem.

Another example is a professional service firm that tried to change partner selection practices and undertook for this end various hierarchical interventions. These brought about some minor changes but they could not revise the overarching path (Erfurt Sandhu 2014).

What do our results add to the two streams of research in question: the theory of organizational path dependence and hierarchy theory? Point of departure was the question whether principles developed in non-hierarchical situations also work in a formal organization with a different logic of functioning. The principles of formal organizations hold that order and obedience determine to a large degree. In other words, the logic of path dependence relies on the forces of emerging, selfreinforcing processes and thereby challenges the logic of hierarchical domination, which is still the predominant view of organizational functioning and in which we typically believe in everyday interactions with organizations. For example, when new CEOs arrive they are typically asked how they want to change the company, thereby implying that hierarchy can deliberately change the system according to new plans. It was, therefore, important to observe whether hierarchical order is strong enough to overcome the power of self-reinforcing dynamics and structural inertia. Our findings systematically demonstrate that self-reinforcing dynamics can actually override the hierarchical order, but in the short run, hierarchical interventions can slow down the dynamics of self-reinforcing processes.

Our results indicate first the necessity to include reflections on the importance of formal authority for path building processes into the theory of organizational path dependence. A complete ignorance of the impact of formal organizations seems no longer adequate. A more comprehensive point of view is needed. What we know from this study is that context matters. Therefore, a next step could be to specify more substantially the contexts that enhance or hinder the building of path dependence. First steps in this direction are suggested by Pierson (2000), who pointed to "murkiness" of the context as a possible mediator (the "murkier" the context, the more likely path dependence emerge). In sum, our results indicate a need for complexifying the path dependence theory. 
Second, our findings not only refer to the theory of organizational path dependence, but also highlight more generally the power of emergent selfreinforcing processes in formal organizations. More often than not, the relevance of emergent processes is simply stated without reflecting on the relationship and the rivalry with formal authority lines. In our study the formal and the emergent (path building) streams in an organization are explicitly juxtaposed and observed as rivaling forces in terms of dominance. Hierarchy proved important, but in most cases (not in all) the power of unintended emergent processes seems to be prevalent in the longer term.

Conversely, when discussing the importance of formal authority, the power of rivaling emergent forces should not be ignored. However, a sweeping generalization on the importance of all emergent organizational processes is not permitted. There is no general overarching theory of emergent phenomena. Emergent processes all have their own logic; take for instance the "garbage-can model" emphasizing random choice (Cohen et al. 1972), or political processes highlighting the interaction of domination strategies (Crozier and Friedberg 1979; Thomas and Davies 2005). Self-reinforcing processes represent a special force with very strong dynamics. The influence of other emergent processes on organizational decision making may be much weaker. Current organizational thought tends to idealize the importance of emergent processes and to underrate the effectiveness of formal authority. A comprehensive organizational theory that systematically includes both formal authority and informal processes does not yet exist. The challenge is that such a theory would have to be paradoxical in nature. It is difficult to accept the validity of formal rules and the power of informal evolutionary processes at the same time. Once again, an exploration of the context may offer a promising avenue here.

Thus, what are the practical implications of our simulations? The study does not provide a specific tool for improving organizational design; rather, it addresses the logic of design, or more generally the "reflective practitioner" (Schön 1991; Johns 2017); that is, aiming to enhance the practitioner's ability for "reflection-in-action." When re-designing organizations, managers and consultants are used to take the effectiveness and dominance of hierarchy for granted. Organization charts reinforce this assumption and this view of organizational functioning. Our study calls this unproblematic action theory into question. Recently, much attention has been given to studies promoting hierarchy-free organizations - or at least flat hierarchies (e.g., Robertson 2016). However, this is not what we are focusing on here. We refer to the effectiveness of the hierarchical relationship facing emergent forces that challenge this functioning. Our study highlights rivaling forces: hierarchy and evolutionary dynamics, such as self-reinforcing processes and path building. The simulation shows that in many situations the hierarchy cannot overrule the self-reinforcing dynamics. This fact is often not noticed, because on the surface the formal relationships are still there and the organization charts are still used. To gain a better understanding of the organizational reality it is, therefore, necessary to have a more complete picture of the forces at work. To manage organizational processes more effectively, it is necessary to be aware of the existence and the potential power of 
self-reinforcing processes. Our study calls for a deeper reflection on the importance of self-reinforcing processes to enrich action theories of practitioners.

\section{Limitations and outlook}

This simulation highlights path building in hierarchical settings and the relative power of self-reinforcing processes. The main result of this simulation indicates clearly that strict hierarchical authority can limit the speed with which lock-in occurs, but it cannot halt path building. The results of this simulation and their implications build on certain assumptions, which of course do not represent the full complexity of organizational interactions and the processes by which they evolve. Organizational path-building processes in practice are doubtless more complex and nuanced than the one modeled in the simulation. For instance, organizational behavior is of course a function of many more attributes than benefitting from complementarities and the resulting tendency to avoid misfit costs. Our model provides a platform to expand the perspective further, for example by investigating other types of self-reinforcing processes and other forms of hierarchy, including more complex relational structures among subunits. Cabral and Kretschmer (2007) present a similar analysis by looking at "forced" adoptions, but in a different context and with a different focus.

There are obviously further limitations to our simulation study. Our modeling of organizational hierarchy represents just one possible solution; there are various alternative approaches. Siggelkow and Rivkin (2006), in their hierarchy conception for instance, focus on a bottom-up process where the department heads can rank accept or reject proposals from the bottom and send a given number of most preferred proposals to the company's upper management for final selection.

This conception is more oriented toward bottom-up initiatives and the acceptance or rejection by hierarchy. Our model focuses more on the classical order and obedience (top-down) principle as the backbone of hierarchy. It may well be that due to its bottom-up (and not top-down) character the Siggelkow and Rivkin-model brings about results, indicating other directions and conclusions.

Moreover, our decision-making model, and especially the utility function controlling the agents' behavior, is derived from theory and not from empirical observations. In further studies, an empirical foundation would be desirable. However, the processes building the agents' motivation and utility are highly complex and, therefore, a simple empirical study would not be sufficient.

Simulation studies are structurally bound to simple theory when modeling complex real-world behavior (Davis et al. 2007). Simplifications applied in this study include the decision problem where agents choose between two alternatives only. In addition, the environment of the organization is assumed to remain stable over time. Environmental changes are, however, common nowadays. Interestingly enough, another simulation study suggests, however, that a changing environment and a more complex decision-making problem do not significantly alter path-building processes in general (Seidel 2013). 
Acknowledgements The authors thank two anonymous reviewers for their valuable comments and constructive suggestions. The authors also gratefully acknowledge generous funding by Deutsche Forschungsgemeinschaft (DFG), Research Training Group (Graduiertenkolleg: Pfade organisatorischer Prozesse) at the School of Business and Economics, Freie Universität Berlin.

Open Access This article is distributed under the terms of the Creative Commons Attribution 4.0 International License (http://creativecommons.org/licenses/by/4.0/), which permits unrestricted use, distribution, and reproduction in any medium, provided you give appropriate credit to the original author(s) and the source, provide a link to the Creative Commons license, and indicate if changes were made.

\section{Appendix 1: Path building for varying degrees of complementarity}

Note 1: The experiments were conducted in a setting with $N=1000$ agents, using the simple model.

Note 2: It can be seen that for $c=0$ and $c=1$ the results confirm those in Sect. 3.2 (Fig. 2). For values between $0<c<1$, averaged cluster density $(x)$ increases in $c$ and stabilizes over time

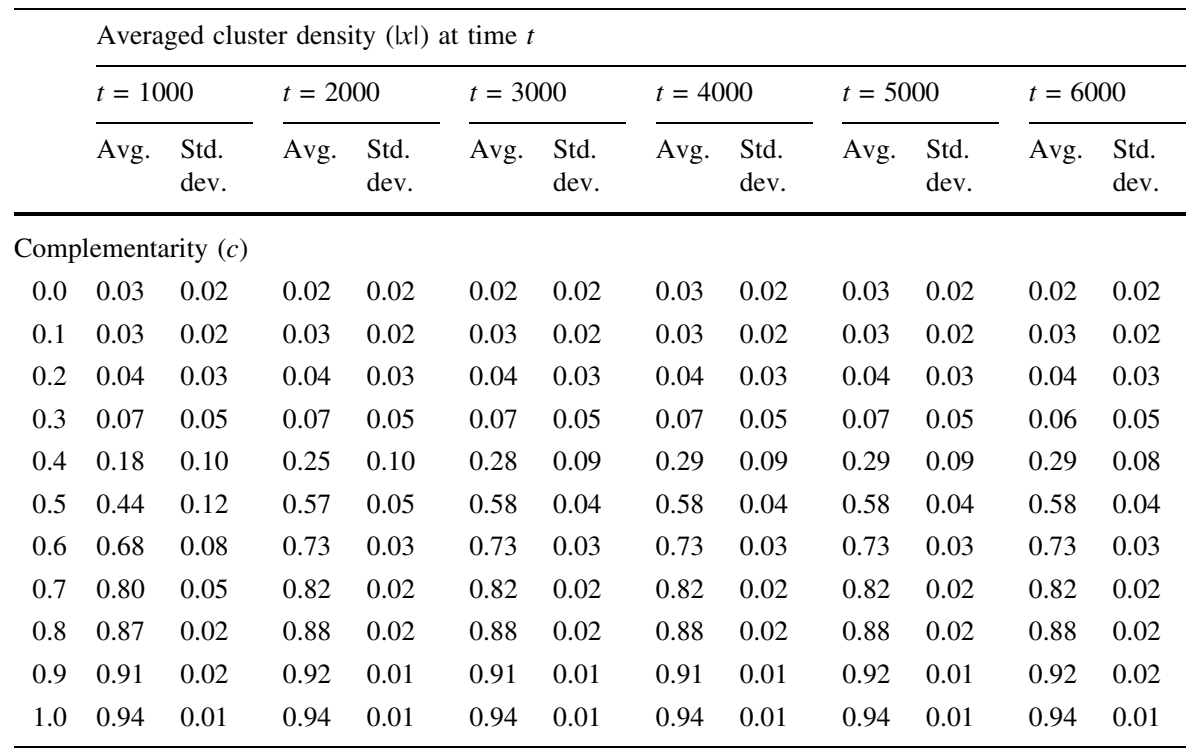

Reports average density of institutional cluster $(|x|)$ within 6000 ticks depending on complementarity $(c)$; for each parameter setting 1000 simulation runs have been calculated.

\section{Appendix 2: Sensitivity to organizational size}

The number of agents was reduced from the initial value of 1000 in hundred steps to 100 and increased to 10,000 in thousand steps. The analysis showed that the system behavior did not depend significantly on the number of agents in the simulation. The results for the extreme points of the sensitivity analysis are shown in Figure B1-2 for 100 agents and Figure B3-4 for 10,000 agents. 

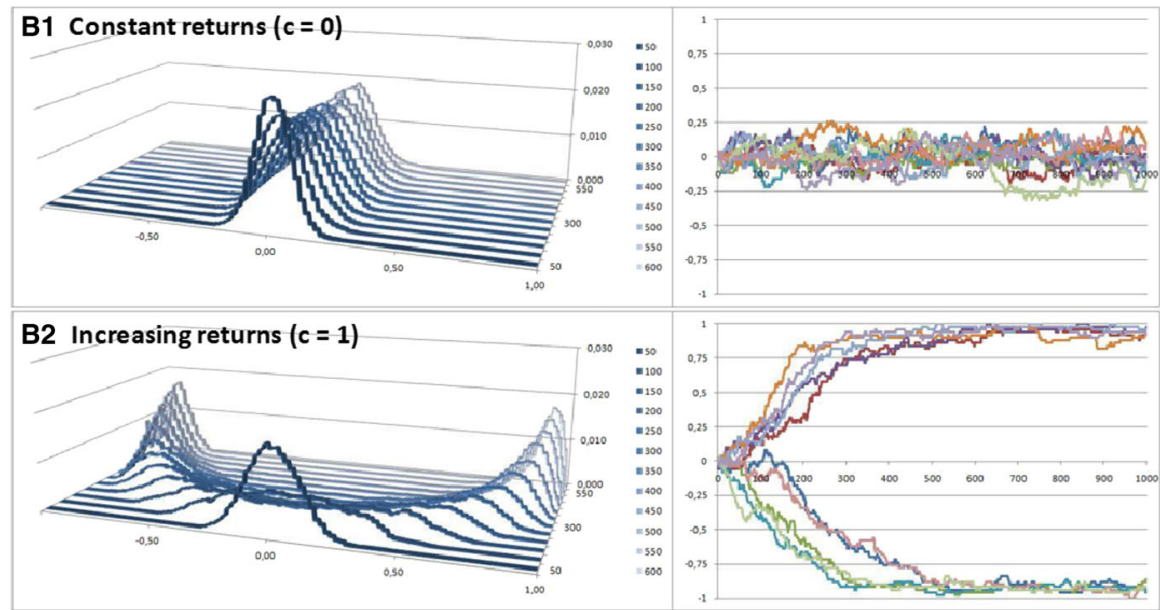

Left: Probability density of $x$ over time; $x$-axis: $x ; y$-axis: probability density over $x$; $z$-axis: time in ticks;

Right: Development of $x$ over time in exemplary simulation runs; $x$-axis: time in ticks; $y$-axis: $x$ over time

It can be seen that the diffusion curves scatter more strongly in the 100-agent case. This is not surprising and can be explained by the fact that the variable degree of distribution is a relative variable. If the population to which the relative variable refers is smaller $(100<10,000)$, the change in behavior of an individual agent has a greater effect on this variable and, therefore, spreads more than with a significantly higher population of 10,000 .

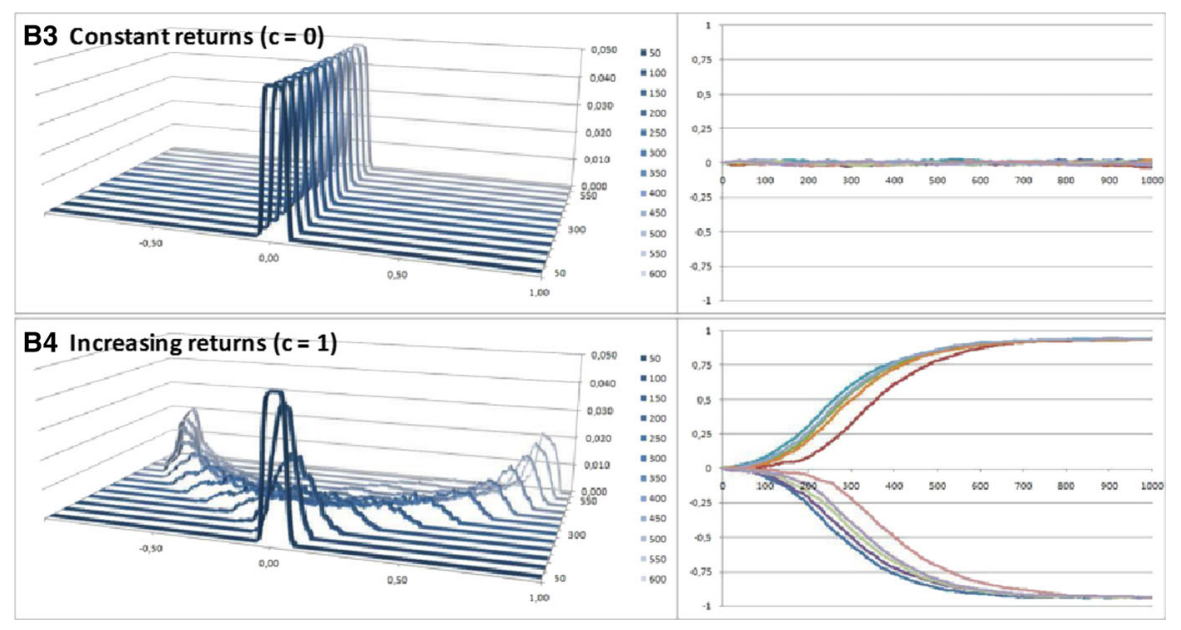

Left: Probability density of $x$ over time; $x$-axis: $x ; y$-axis: probability density over $x$; $z$-axis: time in ticks; 
Right: Development of $x$ over time in exemplary simulation runs; $x$-axis: time in ticks; $y$-axis: $x$ over time

Nevertheless, it can be stated that for both few and a large number of agents the system behavior remains qualitatively stable for both constant and increasing returns, so that one can assume that the mode of action of the "mechanism" that generates the system behavior does not react strongly sensitively to the number of agents. The use of the number of 1000 agents can, therefore, be justified.

\section{Appendix 3: Instrumentality of employee actions}

For this experiment, we extended Eq. (1) as follows: We introduce a new variable $I_{j}$ so that $\mathrm{FTA}_{j}=E_{j} \times V_{j} \times I_{j}$ where $I_{j}$ refers to the instrumentality of an agent's action. All other factors of the model remain unchanged. The instrumentality gives the leader the possibility to ensure that the individual's goal becomes congruent with the organizational goal. To do this, the leader may introduce rewards or punishments. In our implementation, we introduce a punishment $p$ where $I=(1-p)$ if and only if the individual's action in round $t-1$ did not match the action of the leader during that round. The variable $p$ is continuous and distributed on an interval from 0 to 1 . If the action of the individual conforms to the action of the leader in $t-1, p$ is set to 0 (and thus nothing happens).

The figure below reports results from two simulations with varying organizational hierarchies. In Figure A, the organization had a span of control of 2, whereas in Fig. B it had a span of control of 10. In both cases, we see that before the intervention has occurred, the system converges to a cluster density of $x \sim 0.6$. After the intervention, the system tips and converges to a new steady solution.

Analysis of the system behavior suggests that for $p<$ threshold-value, the intervention has only a destabilizing effect but does not break the dominant solution. In turn, for $p>$ threshold value, the system tips as shown in the two exemplary simulations below.

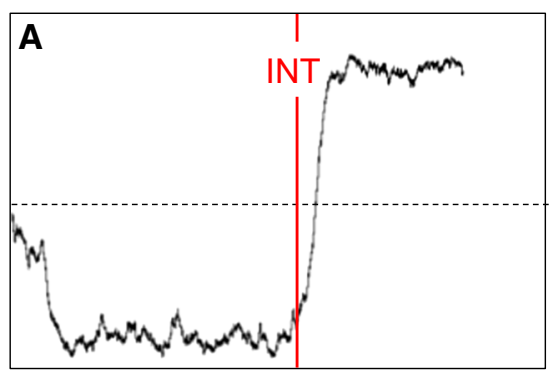

$c=0.4, l i=0.2$ (with $p=0.15$ after intervention (here: marked by INT) SPAN OF CONTROL $=2$

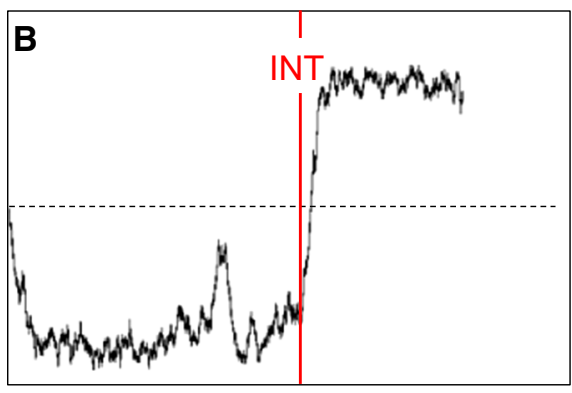

$c=0.4, l i=0.2$ (with $p=0.15$ after intervention (here: marked by INT) SPAN OF CONTROL $=10$ 


\section{References}

Arthur, W.B. 1989. Competing technologies, increasing returns, and lock-in by historical events. Economic Journal 99: 116-131.

Arthur, W.B. 1990. Positive feedbacks in the economy. Scientific American 262: 80-85.

Arthur, W.B. 1994. Increasing returns and path dependency in the economy. Ann Arbor, MI: University of Michigan Press.

Arthur, W.B. 2018. Self-reinforcing mechanisms in economics. In The economy as an evolving complex system, ed. Philip W. Anderson, 9-32. Boca Raton: CRC Press.

Blau, P.M. 1957. Formal organization: dimensions of analysis. American Journal of Sociology 63: 58-69.

Blau, P.M., and W.R. Scott. 1962. Formal organizations: A comparative approach. Stanford, CA: Stanford University Press.

Burgelman, R.A. 2002. Strategy is destiny. How strategy-making shapes a company's future. New York: Free Press.

Cabral, L.M.B., and T. Kretschmer. 2007. Standard battles and public policy. In Standards and public policy, ed. Shane Greenstein and Victor Stango, 329-344. Cambridge: Cambridge Univ. Press.

Cohen, M.D., J.G. March, and J.P. Olsen. 1972. A garbage can model of organizational choice. Administrative Science Quarterly 17: 1-25.

Cowan, R. 1990. Nuclear power reactors: A study in technological lock-in. Journal of Economic History 50: 541-567.

Cowan, R., and P. Gunby. 1996. Sprayed to death: Path-dependence, lock-in and pest control strategies. Economic Journal 106: 521-542.

Crozier, M., and E. Friedberg. 1979. Das Spiel als Instrument organisierten Handelns. In: dies., Macht und Organisation. Die Zwänge kollektiven Handelns. Königstein Ts.: Athenäum: 56-76.

Cusumano, M.A., Y. Mylonadis, and R.S. Rosenbloom. 1992. Strategic maneuvering and mass-market dynamics: The triumph of VHS over beta. Business History Review 66: 51-94.

Danneels, E. 2011. Trying to become a different type of company: Dynamic capability at Smith Corona. Strategic Management Journal 32: 1-31.

David, P.A. 1985. Clio and the economics of QWERTY. The American Economic Review 75: 332-337.

David, P.A. 1994. Why are institutions the "Carriers of History"? Path dependence and the evolution of conventions, organizations and institutions. Structural Change and Economic Dynamics 5: 205-220.

David, P.A. 2001. Path dependence, its critics and the quest for "historical economics". In Evolution and path dependence in economic ideas: Past and present, ed. Patrice Garrouste, 15-40. Cheltenham,Northampton: Elgar Publishing.

David, P.A., and J. Bunn. 1988. The economics of gateway technologies and network evolution: Lessons from electricity supply history. Information Economics and Policy 3: 165-202.

Davies, B. 2018. Exploring Chaos: Theory and experiment. Boca Raton: CRC Press.

Davis, J.P., K.M. Eisenhardt, and C.B. Bingham. 2007. Developing theory through simulation methods. Academy of Management Review 32: 480-499.

Dobusch, L., and E. Schüßler. 2013. Theorizing path dependence: A review of positive feedback mechanisms in technology markets, regional clusters, and organizations. Industrial and Corporate Change 22: 617-647.

Eggers, J.P., and K.F. Park. 2018. Incumbent adaptation to technological change: The past, present, and future of research on heterogeneous incumbent response. Academy of Management Annals 12: 357-389.

Eisenhardt, K.M., and J.A. Martin. 2000. Dynamic capabilities: What are they? Strategic Management Journal 21: 1105-1121.

Erfurt, Sandhu P. 2014. Selektionspfade im topmanagement. Berlin: Springer Gabler.

Farmer, J.D., and D. Foley. 2009. The economy needs agent-based modelling. Nature 460: 685-686.

Fouquet, R. 2016. Path dependence in energy systems and economic development. Nature Energy 1: Article 16098.

Gilbert, N., and K.G. Troitzsch. 2005. Simulation for the social scientist. Maidenhead: Open University Press.

Harrison, J.R., Z. Lin, G.R. Carroll, and K.M. Carley. 2007. Simulation modeling in organizational and management research. Academy of Management Review 32: 1229-1245.

Hernes, T. 2014. A process theory of organization. Oxford: Oxford University Press. 
Hodgson, G.M., and T. Knudsen. 2004. The complex evolution of a simple traffic convention: The functions and implications of habit. Journal of Economic Behavior \& Organization 54: 19-47.

Johns, C. 2017. Becoming a reflective practitioner, 5th ed. Hoboken, New Jersey: Wiley.

Katz, F.E. 1965. Explaining informal work groups in complex organizations: The case for autonomy in structure. Administrative Science Quarterly 10: 204-223.

Katz, M.L., and C. Shapiro. 1985. Network externalities, competition, and compatibility. The American Economic Review 75: 424-440.

Kremser, W., and G. Schreyögg. 2016. The dynamics of interrelated routines: Introducing the cluster level. Organization Science 27:698-721

Langley, A. 2009. Studying processes in and around organizations. The Sage Handbook of Organizational Research Methods, 409-429.

Law, A.M. 2014. Simulation modeling and analysis, 5th ed. Boston: McGraw-Hill.

Liebowitz, S.J., and S.E. Margolis. 1990. The fable of the keys. Journal of Law and Economics 33: 1-25.

Liebowitz, S.J., and S.E. Margolis. 2013. the troubled path of the lock-in movement. Journal of Competition Law and Economics 9: 125-152.

Macal, C.M., and M.J. North. 2010. Tutorial on agent-based modelling and simulation. Journal of Simulation 4 (3): 151-162.

Meyer, J.W., and B. Rowan. 1977. Institutionalized Organizations: Formal structure as a myth and ceremony. American Journal of Sociology 83: 340-363.

Milgrom, P., and J. Roberts. 1995. Complementarities and fit: Strategy, structure, and organizational change in manufacturing. Journal of Accounting and Economics 19: 179-208.

Misztal, B.A. 2002. Informality: Social theory and contemporary practice. New York, NY: Routledge.

North, D.C. 1990. Institutions, institutional change and economic performance. Cambridge: Cambridge University Press.

Page, S.E. 2006. Path dependence. Quarterly Journal of Political Science 1: 87-115.

Pettigrew, T.F. 1971. Racially separate or together?. New York: McGraw-Hill.

Pierson, P. 2000. Increasing returns, path dependence, and the study of politics. American Political Science Review 94: 251-267.

Reeves, M., and M. Deimler. 2011. Adaptability: The new competitive advantage. Harvard Business Review 89: 134-141.

Rivkin, J.W., and N. Siggelkow. 2003. Balancing search and stability: Interdependencies among elements of organizational design. Management Science 49: 290-311.

Robertson, B.J. 2016. Holacracy: the revolutionary management system that abolishes hierarchy. New York, NY: Portfolio Penguin.

Sackmann, S.A. 1992. Culture and subcultures: An analysis of organizational knowledge. Administrative Science Quarterly 37: 140-161.

Schön, D.A. 1991. The reflective practitioner: How professionals think in action. London: Taylor \& Francis.

Schneider, L. 2014. Firm value in emerging network industries. Information Economics and Policy 26: 75-87.

Schreyögg, G., J. Sydow, and P. Holtmann. 2011. How history matters in organisations: The case of path dependence. Management and Organizational History 6: 81-100.

Schreyögg, G., and J. Sydow. 2011. Organizational path dependence: A process view. Organization Studies 32: 321-335.

Seidel E. 2013. Path dependence and the environmental context: An inquiry into the effects of environmental complexity and turbulence on path dependence in organizational learning. Dissertation, Berlin: Freie Universität Berlin.

Selznick, P. 1948. Foundations of the theory of organization. American Sociological Review 13: 25-35.

Siggelkow, N. 2011. Firms as systems of interdependent choices. Journal of Management Studies 48: 1126-1140.

Siggelkow, N., and J.W. Rivkin. 2005. Speed and search: Designing organizations for turbulence and complexity. Organization Science 16: 101-122.

Siggelkow, N., and J.W. Rivkin. 2006. When exploration backfires: Unintended consequences of multilevel organizational search. Academy of Management Journal 49: 779-795.

Spiegel, M., T. Schmiedel, and J. vom Brocke. 2017. What makes change harder or easier. MIT Sloan Management Review 58: 88-89.

Stieglitz, N., T. Knudsen, and M.C. Becker. 2016. Adaptation and inertia in dynamic environments. Strategic Management Journal 37: 1854-1864. 
Sydow, J., G. Schreyögg, and J. Koch. 2009. Organizational path dependence: Opening the black box. Academy of Management Review 34: 689-709.

Thomas, R., and A. Davies. 2005. Theorizing the micro-politics of resistance: New public management and managerial identities in the UK public services. Organization Studies 26: 683-706.

Tripsas, M., and G. Gavetti. 2000. Capabilities, cognition, and inertia: Evidence from digital imaging. Strategic Management Journal 21: 1147-1161.

Viswanathan, S. 2005. Competing across technology-differentiated channels: The impact of network externalities and switching costs. Management Science 51: 483-496.

Vroom, V.H. 1964. Work and motivation. New York: Wiley.

Weber, M. 2009. From Max weber: Essays in sociology. Abingdon, Oxon, New York, NY: Routledge.

Weidlich, W., and G. Haag. 1983. Concepts and models of quantitative sociology: The dynamics of interacting populations. Berlin and Heidelberg: Springer.

Worley, C.G., T.D. Williams, and E.E. Lawler III. 2014. The agility factor: Building adaptable organizations for superior performance. New York, NY: John Wiley and Sons Inc.

Publisher's Note Springer Nature remains neutral with regard to jurisdictional claims in published maps and institutional affiliations. 